\title{
Адсорбция кислорода на низкоиндексных поверхностях сплава $\mathrm{Ti}_{3} \mathrm{Al}$
}

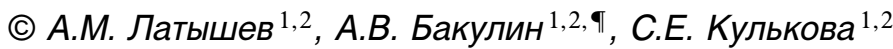 \\ ${ }^{1}$ Институт физики прочности и материаловедения СО РАН, \\ Томск, Россия \\ ${ }^{2}$ Национальный исследовательский Томский государственный университет, \\ Томск, Россия \\ I E-mail: bakulin@ispms.tsc.ru
}

(Поступила в Редакцию 14 фревраля 2017 г.)

Атомная и электронная структура трех поверхностей — (0001), (1ㅣㅣㅇ) и $(11 \overline{2} 0)-$ сплава $\mathrm{Ti}_{3} \mathrm{Al}$ рассчитана методом проекционных присоединенных волн в рамках теории функционала электронной плотности. Проведена оценка поверхностных энергий в зависимости от химического потенциала алюминия, что позволило построить диаграмму стабильности рассмотренных поверхностей. Изучена адсорбция кислорода на разно ориентированных поверхностях сплава. Установлено, что наиболее предпочтительными позициями для адсорбции кислорода являются ямочные позиции на поверхностях $(0001)$ и $(11 \overline{2} 0)_{\mathrm{Ti}-\mathrm{Al}}$ и мостиковые позиции на поверхности $(1 \overline{1} 00)_{\text {Ti-Al-1. }}$ Обсуждаются структурные и электронные факторы, обусловливающие их энергетическую предпочтительность. Показано, что независимо от ориентации поверхности кислород „предпочитает“ обогащенные титаном позиции. Обсуждается влияние кислорода на атомную и электронную структуру низкоиндексных поверхностей. Установлено, что при низких концентрациях кислорода формирование его химической связи с атомами титана и/или алюминия поверхностных и подповерхностных слоев приводит к появлению низколежащих состояний, отщепленных от дна валентных зон металлов, что сопровождается образованием псевдощели и ослаблением металлических связей $\mathrm{Ti}-\mathrm{Al}$ в поверхностных слоях.

Работа выполнена при финансовой поддержке РФФИ (грант № 14-02-91150_ГФЕН), а также частично в рамках проекта № 23.1.2 ИФПМ СО РАН и поддержана программой повышения конкурентоспособности ТГУ.

Численные расчеты выполнены на суперкомпьютере SKIF-Cyberia в Томском государственном университете, а также с использованием ресурсов суперкомпьютерного комплекса МГУ им. М.В. Ломоносова.

DOI: 10.21883/FTT.2017.09.44858.036

\section{1. Введение}

Алюминиды титана благодаря хорошим механическим свойствам, в частности высокой удельной прочности и температуре плавления, высоким модулям упругости, эластичности и жаропрочности [1-3], широко используются в аэрокосмической, авиационной и автомобильной промышленности. Несмотря на интенсивное изучение экспериментальными и теоретическими методами на протяжении последних десятилетий, эти интерметаллические сплавы по-прежнему привлекают внимание исследователей как с технологической, так и фундаментальной точки зрения. В то же время недостаточная коррозионная стойкость сплавов $\mathrm{Ti}_{3} \mathrm{Al}$ и $\mathrm{TiAl}$ ограничивает их использование при высоких температурах, a сплав $\mathrm{TiAl}_{3}$, обнаруживающий максимальную стойкость к окислению, является достаточно хрупким. Разработка новых высокотемпературных конструкционных материалов на основе сплавов $\mathrm{Ti}-\mathrm{Al}$ является важной задачей современного материаловедения. Экспериментальные исследования [4-7] показали, что низкая коррозионная стойкость сплавов с меньшим содержанием алюминия связана с ростом смешанных оксидных слоев, содержащих оксиды титана и алюминия. Известно, что формирующиеся на поверхности сплошные оксидные слои являются эффективными барьерами для диффузии кислорода, что ограничивает скорость роста оксидных пленок даже при высоких температурах [4-7]. В связи с этим необходимо понимать микроскопические механизмы окисления сплавов $\mathrm{Ti}-\mathrm{Al}$ в зависимости от их состава, а также особенности взаимодействия кислорода с атомами поверхностных слоев, что позволит установить основные факторы, влияющие на кинетику роста оксидных слоев и их свойства. Известно, что энергии образования $\mathrm{TiO}_{2}$ и $\mathrm{Al}_{2} \mathrm{O}_{3}$ равны -9.78 и $-11.58 \mathrm{eV}$ [8] соответственно. Считается, что металл, который имеет бо́льшую энергию образования оксида по модулю, окисляется первым и сегрегирует к поверхности даже при низких температурах и концентрациях кислорода. Кроме того, титан может окисляться с образованием ряда оксидов $\left(\mathrm{Ti}_{2} \mathrm{O}, \mathrm{TiO}, \mathrm{Ti}_{2} \mathrm{O}_{3}, \mathrm{Ti}_{3} \mathrm{O}_{5}, \mathrm{TiO}_{2}\right)$, тогда как алюминий не образует промежуточных оксидных фаз, и $\mathrm{Al}_{2} \mathrm{O}_{3}$ обнаруживается на поверхности сплавов $\mathrm{Ti}-\mathrm{Al}$ даже при низких температурах. В связи с этим титан может играть важную роль в формировании оксидных пленок на поверхности сплавов в зависимости от его концентрации. В эксперименте достаточно трудно получить информацию на микроскопическом уровне о начальной стадии окисления поверхности сплавов вследствие влияния различных факторов на этот процесс, таких как наличие примесей, структура поверхности, 
возможности экспериментальных методов и их условия. Поэтому все больше возрастает роль теоретических подходов, таких как методы, применяемые в рамках теории функционала электронной плотности (ФЭП), которые позволяют непосредственно получить значения энергий связи кислорода для различных позиций на поверхности сплава в зависимости от ее ориентации.

По сравнению с металлическими поверхностями, для которых механизмы окисления интенсивно изучались теоретическими методами, интерметаллическим сплавам уделялось меньшее внимание. Одной из первых теоретических работ, посвященных изучению процессов окисления поверхности сплавов, является публикация Лозового с соавторами [9], в которой изучалась адсорбция кислорода на поверхности $\mathrm{NiAl}(110)$. В настоящее время известно несколько работ $[10-20]$, в которых рассматривались низкоиндексные поверхности сплавов $\mathrm{Ti}-\mathrm{Al}$ и их взаимодействие с кислородом, при этом наиболее изученным остается сплав $\gamma$-TiAl. В $[10,11]$ исследовалась адсорбция кислорода на поверхности $\gamma$-TiAl(111). Было показано, что наиболее предпочтительными для адсорбции кислорода являются позиции, обогащенные титаном, а формирование связей металлов с кислородом приводит к ослаблению металлической связи в сплаве. Отметим, что в работе [10] рассматривалось также влияние концентрации кислорода на атомную структуру поверхности (111). В частности, было установлено, что кислород, внедряясь в подповерхностный слой, ведет к образованию смешанных разупорядоченных оксидных слоев со значительными структурными искажениями. Было отмечено, что стабилизировать поверхностный оксид и улучшить его упорядочение можно с помощью отжига. В работе [11] изучалось влияние эффектов сегрегации на адсорбцию кислорода на поверхности $\gamma$-TiAl(111). Авторы показали, что сегрегация алюминия понижает поверхностную энергию, при этом адсорбция кислорода на поверхности с двумя антиструктурными Al-дефектами (Al-antisite) подобна адсорбции на соответствующей поверхности чистого алюминия, а энергия связи кислорода с поверхностью понижается с увеличением его концентрации. Отметим, что стабильность низкоиндексных поверхностей сплава $\gamma$-TiAl рассматривалась в работе [12]. Кроме того, адсорбция кислорода на других поверхностях (001), (100), (110) сплава $\gamma$-TiAl изучалась в [13-16]. Так, в [13] было установлено, что наиболее предпочтительной позицией для адсорбции кислорода на поверхности $\operatorname{TiAl}(001)$, оканчивающейся титаном, является вершинная над атомом титана поверхностного слоя $\left(T_{\mathrm{Ti}}\right)$, тогда как в [14-16] найдено, что предпочтительной является ямочная позиция над атомом алюминия подповерхностного слоя $\left(H_{\mathrm{Al}}\right)$. Кроме того, в наших ранних работах $[15,16]$ изучалась диффузия кислорода как в объеме сплава, так и с поверхности в глубь материала. По нашим сведениям имеется лишь одна работа [17], в которой рассматривалась адсорбция кислорода на поверхности сплава $\mathrm{TiAl}_{3}$. В ней рассчитывались поверхностные энергии низкоиндексных поверхностей в зависимости от их окончания и было показано, что на поверхностях (001) и (110), оканчивающихся алюминием, наблюдается приоритет окисления алюминия над окислением титана. На смешанном окончании данных поверхностей взаимодействие с алюминием превалирует над окислением титана только при низких концентрациях кислорода до 1.5 монослоя, что согласуется с экспериментом [1].

Имеется несколько работ [18-20], в которых изучались микроскопические механизмы окисления стехиометрической поверхности $\mathrm{Ti}_{3} \mathrm{Al}(0001)$. В [18] проводился анализ влияния антиструктурных дефектов на энергетическую стабильность данной поверхности, в том числе при увеличении концентрации кислорода. Было установлено, что поверхность $\mathrm{Ti}_{3} \mathrm{Al}(0001)-3 \mathrm{Al}$ с тремя алюминиевыми дефектами в поверхностном слое является наиболее стабильной в пределе высоких концентраций алюминия. Кроме того, авторы показали, что адсорбция кислорода усиливает сегрегацию алюминия к поверхности, а также подтвердили образование двухфазной оксидной системы, что согласуется с экспериментом [21]. В [19] изучалась адсорбция молекулярного кислорода также на стехиометрической поверхности $\mathrm{Ti}_{3} \mathrm{Al}(0001)$. Было показано, что молекулы кислорода в основном диссоциируют, при этом атомы кислорода стремятся занять наиболее энергетически предпочтительные ямочные позиции на поверхности $\mathrm{Ti}_{3} \mathrm{Al}(0001)$. В последующей работе этих авторов [20] была рассмотрена адсорбция атомарного кислорода на той же поверхности, в том числе при увеличении степени покрытия кислородом до одного монослоя. В целом в $[19,20]$ было показано, что наибольшая энергия связи кислорода с поверхностью соответствует позициям, в которых адатом кислорода формирует связи преимущественно с атомами титана. В то же время в ранних работах, упомянутых выше, не обсуждалась стабильность низкоиндексных поверхностей сплава $\mathrm{Ti}_{3} \mathrm{Al}$, а также не изучалась адсорбция кислорода на других поверхностях.

Таким образом, целью настоящей работы является сравнительное изучение энергетики связи кислорода на трех низкоиндексных поверхностях: (0001), (1100) и (1120), что позволит глубже понять механизмы связи кислорода на разноориентированных поверхностях в зависимости от состава поверхностных слоев и, как следствие, начальный этап окисления поверхности сплава $\mathrm{Ti}_{3} \mathrm{Al}$.

\section{2. Метод расчета}

Расчет атомной и электронной структуры низкоиндексных поверхностей сплава $\mathrm{Ti}_{3} \mathrm{Al}$ проводился методом проекционных присоединенных волн (PAW) в плосковолновом базисе [22,23], реализованном программным кодом VASP [24-26], с обобщенным градиентным приближением для обменно-корреляционного функционала в форме GGA-PBE [27]. Максимальная энергия плоских 
волн из базисного набора была равна $550 \mathrm{eV}$. При расчете электронной структуры объемного сплава интегрирование по зоне Бриллюэна проводилось с использованием Г-центрированной сетки $k$-точек $13 \times 13 \times 17$. Сходимость считалась достигнутой, если разница в полных энергиях для двух последующих итераций не превышала $10^{-5} \mathrm{eV}$.

Для расчета поверхностной энергии низкоиндексных поверхностей сплава $\mathrm{Ti}_{3} \mathrm{Al}$ с разной ориентацией применялся подход многослойных симметричных пленок, разделенных промежутком вакуума не менее $15 \AA$. Для каждой поверхности оптимальное число атомных слоев в пленке определялось на основе тестовых расчетов поверхностной энергии, которые показали, что увеличение числа слоев в пленке свыше 9, 14 и 16 для поверхностей $(0001),(11 \overline{2} 0)$ и (1100) соответственно не приводит к существенным изменениям поверхностной энергии, а точность расчета поверхностной энергии составляет $\sim 0.005 \mathrm{~J} / \mathrm{m}^{2}$. Релаксация положений атомов поверхностных слоев проводилась с использованием динамики Ньютона до достижения сил на атомах менее $0.01 \mathrm{eV} / \AA ̊$. В случае поверхности (0001) использовалась $\Gamma$-центрированная сетка $k$-точек $7 \times 7 \times 1$, а сетка $k$-точек $5 \times 7 \times 1$, генерируемая по схеме Монхорста-Пака [28], применялась для расчета поверхностей с ориентацией $(11 \overline{2} 0)$ и (11̄00).

Адсорбция кислорода на низкоиндексных поверхностях сплава $\mathrm{Ti}_{3} \mathrm{Al}$ изучалась в модели несимметричных пленок, описанной в нашей ранней работе [16]. Отметим, что кислород может адсорбироваться в различных позициях на поверхности сплава в зависимости от ее ориентации. Как правило, рассматриваются высокосимметричные позиции в пустотах, координированных тремячетырьмя поверхностными атомами (ямочные), между двумя атомами (мостиковые) и над поверхностными атомами (вершинные). Атомы трех слоев с нижней стороны пленки фиксировались в позициях, соответствующих объемным, тогда как положения атомов остальных слоев оптимизировались. Энергия адсорбции атома кислорода рассчитывалась по формуле

$$
E_{\mathrm{ads}}=-\left[E_{\mathrm{O} / \mathrm{Ti}_{3} \mathrm{Al}}-E_{\mathrm{Ti}_{3} \mathrm{Al}}-(1 / 2) E_{\mathrm{O}_{2}}\right],
$$

где $E_{\mathrm{O} / \mathrm{Ti}_{3} \mathrm{Al}}$ и $E_{\mathrm{Ti}_{3} \mathrm{Al}}-$ полные энергии поверхности с кислородом и без него, а $E_{\mathrm{O}_{2}}-$ полная энергия молекулы кислорода, рассчитанная в пустой ячейке со сторонами $12 \times 12 \times 12 \AA$. Множитель $1 / 2$ соответствует адсорбции кислорода на одной поверхности сплава. Энергия связи кислорода на поверхности рассчитывалась по формуле

$$
E_{b}=-\left[E_{\mathrm{O} / \mathrm{Ti}_{3} \mathrm{Al}}-E_{\mathrm{Ti}_{3} \mathrm{Al}}-E_{\mathrm{O}}\right],
$$

где $E_{\mathrm{O}}-$ полная энергия атома кислорода. Известно, что в спин-поляризованном расчете энергия связи в молекуле кислорода на $\sim 1 \mathrm{eV}[15,29]$ превышает экспериментальное значение $(5.12 \mathrm{eV}$ [30]). Чтобы скомпенсировать неточность расчетов в оценках энергий адсорбции кислорода в рамках ФЭП, часто используется

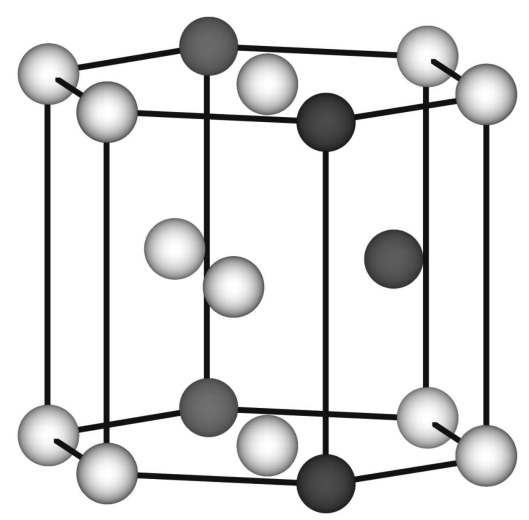

Рис. 1. Атомная структура сплава $\alpha_{2}-\mathrm{Ti}_{3} \mathrm{Al}$. Атомы титана и алюминия показаны светлыми и темными шарами соответственно.

экспериментальное значение энергии связи. В данном подходе полная энергия молекулы кислорода в нашем расчете была равна $8.23 \mathrm{eV}$. Отметим, что теоретическое значение энергии молекулы кислорода $9.86 \mathrm{eV}$ хорошо согласуется со значением $9.80 \mathrm{eV}$, полученным в работе [11].

\section{3. Результаты и обсуждение}

3.1. Свойства объемного сплава $\mathrm{Ti}_{3} \mathrm{Al}$. Сплав $\mathrm{Ti}_{3} \mathrm{Al}$ имеет гексагональную плотноупакованную структуру типа $D 0_{19}$, представленную на рис. 1 , которая характеризуется пространственной группой 194. Рассчитанные параметры решетки сплава $(a$ и $c$ ) для основного состояния, упругие константы $C_{i j}$ и объемный модуль упругости $B$ приведены в табл. 1. Сравнение теоретических параметров решетки с имеющимися данными показывает, что они отличаются от эксперимен-

Таблица 1. Параметры решетки и упругие модули сплава $\mathrm{Ti}_{3} \mathrm{Al}$ в сравнении с имеющимися экспериментальными и теоретическими данными

\begin{tabular}{c|c|c|c|c}
\hline Параметр & $\begin{array}{c}\text { Наш } \\
\text { расчет }\end{array}$ & Расчет [31] & Расчет [32] & Эксперимент \\
\hline$a, \AA$ & 5.736 & 5.72 & 5.64 & $5.77^{*}$ \\
$c, \AA$ & 4.639 & 4.63 & 4.57 & $4.62^{*}$ \\
$c / a$ & 0.809 & 0.81 & 0.81 & $0.80^{*}$ \\
$C_{11}, \mathrm{GPa}$ & 193 & 185 & 221 & $183^{* *}$ \\
$C_{12}, \mathrm{GPa}$ & 90.7 & 83 & 71 & $89.1^{* *}$ \\
$C_{13}, \mathrm{GPa}$ & 66.6 & 63 & 85 & $62.6^{* *}$ \\
$C_{33}, \mathrm{GPa}$ & 235.8 & 231 & 238 & $225^{*}$ \\
$C_{44}, \mathrm{GPa}$ & 55.5 & 57 & 69 & $64.1^{* *}$ \\
$C_{66}, \mathrm{GPa}$ & 51.1 & 61 & 75 & $47.0^{* *}$ \\
$B, \mathrm{GPa}$ & 118.8 & - & 129 & $113^{* *}$
\end{tabular}

* Данные [33].

** Данные [34]. 

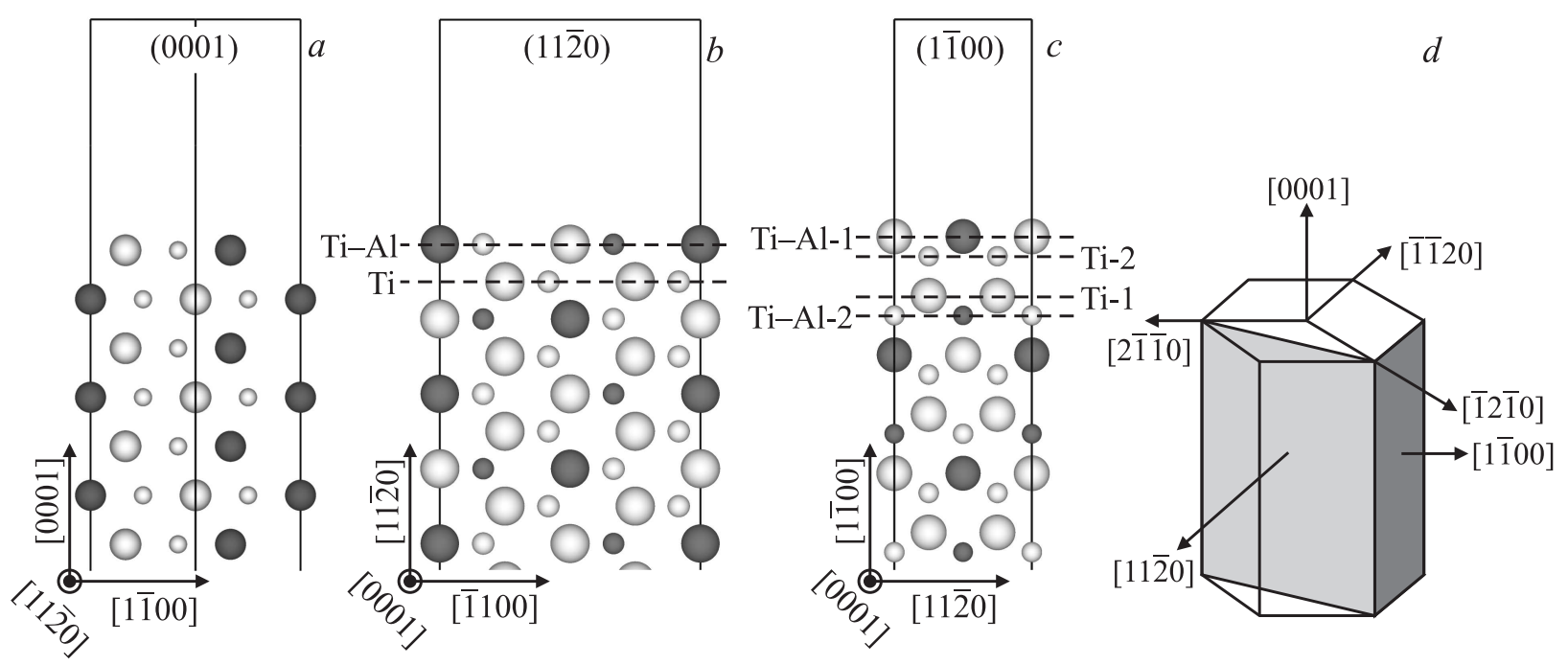

Рис. 2. Атомная структура низкоиндексных поверхностей (0001) (a), (1120) (b) и (1100) (c) сплава Тiз $\mathrm{Al}$ (вид сбоку), а также положение соответствующих кристаллографических плоскостей в гексагональной ячейке сплава $(d)$. Маленькими и большими шарами показаны атомы, лежащие в разных плоскостях. Обозначение атомов такое же, как на рис. 1.

тальных значений менее чем на $0.6 \%$. Упругие константы показывают небольшое отклонение от значений, полученных в ранних расчетах [31,32] с использованием других методов в рамках ФЭП, и также находятся в хорошем согласии с экспериментальными данными [34], измеренными при $3.3 \mathrm{~K}$ и экстраполированными на нулевую температуру. Как показано в работе [34], упругие константы изменяются на $1.3-6.2 \%$ при повышении температуры до $270 \mathrm{~K}$. Отметим, что теоретические упругие константы сплавов отличаются от эксперимента в пределах 5-12\%, и их значения сильно зависят от приближения для обменно-корреляционного функционала и числа $k$-точек, по которым проводится интегрирование по зоне Бриллюэна. Известно, что значение объемного модуля упругости зависит от метода его расчета. Если $B$ оценивается по уравнению Мурнагана [35] с использованием полных энергий, рассчитанных в зависимости от объема сплава, то его значение согласуется с экспериментом лучше, чем оценка по упругим константам. Электронный энергетический спектр и плотности электронных состояний сплава $\mathrm{Ti}_{3} \mathrm{Al}$ подобны приведенным в ранних работах [36-38] и поэтому не обсуждаются. Расчеты структурных и электронных свойств сплава свидетельствуют об адекватности метода и позволяют надеяться на то, что его использование для расчетов сорбции кислорода в объеме сплава и на его поверхностях обеспечит достоверные результаты.

Энергии адсорбции кислорода, рассчитанные по формуле, аналогичной (1), в сплаве $\mathrm{Ti}_{3} \mathrm{Al}$ в октаэдрических $(O)$ и тетраэдрических позициях хорошо согласуются с результатами теоретической работы [39]. Энергия адсорбции кислорода в наиболее предпочтительной $O 1$-позиции равна $6.22 \mathrm{eV}(6.23 \mathrm{eV}$ [39]). Отметим, что данная позиция имеет среди ближайших соседей только атомы титана, тогда как меньшее на $1.54 \mathrm{eV}$ значение было получено для О2-позиции, которая находится в октаэдре, образованном четырьмя атомами титана и двумя атомами алюминия. Адсорбция кислорода в тетраэдрической позиции, когда атом алюминия находится в его основании, приводит к его смещению в гексаэдрическую позицию, в которой он находится в базальной плоскости в треугольнике, образованном двумя атомами титана и одним атомом алюминия, при этом энергия адсорбции лишь на $0.10 \mathrm{eV}$ меньше, чем в O2-позиции. При адсорбции в тетраэдре с алюминием в его вершине атом кислорода не смещается, а его энергия адсорбции составляет $3.77 \mathrm{eV}(3.83 \mathrm{eV}$ [39]). Отметим, что экспериментальные исследования с помощью дифракции нейтронов [40] также указывают на то, что атомы кислорода предпочтительнее занимают октаэдрические O1-позиции.

3.2. Энергетическая стабильность низкоиндексных поверхностей $\mathrm{Ti}_{3} \mathrm{Al}$. На рис. 2 представлена атомная структура трех рассмотренных поверхностей сплава $\mathrm{Ti}_{3} \mathrm{Al}$. Как видно из рис. 2, $a$, поверхность (0001) имеет только окончание стехиометрического состава, тогда как для поверхностей $(11 \overline{2} 0)$ и $(1 \overline{1} 00)$ возможно два и четыре окончания соответственно (рис. 2, b,c). Например, $\mathrm{Ti}_{3} \mathrm{Al}(1 \overline{1} 00)$ может оканчиваться как атомным слоем титана, так и смешанным слоем $\mathrm{Ti}-\mathrm{Al}$, при этом состав подповерхностного слоя может также различаться. Поэтому если поверхностный и подповерхностный слои образованы атомами титана, то такое окончание будем обозначать Ті-2, а в случае смешанного подповерхностного слоя такое окончание поверхности будем обозначать Ті-1. Аналогичный подход используется и в случае смешанного поверхностного слоя. Таким образом, индекс (Ті или $\mathrm{Ti}-\mathrm{Al}$ ) указывает на то, каким атомным слоем заканчивается поверхность. 
Таблица 2. Релаксация первого $\left(\Delta d_{12}\right)$, второго $\left(\Delta d_{23}\right)$ и третьего $\left(\Delta d_{34}\right)$ межслоевых расстояний для чистых поверхностей $\mathrm{Ti}_{3} \mathrm{Al}$, а также расщепление $\varepsilon$ смешанного слоя, ближайшего к поверхности

\begin{tabular}{c|c|c|c|c|c|c|c}
\hline \multirow{2}{*}{ Параметр } & \multicolumn{7}{|c}{ Поверхность } \\
\cline { 2 - 8 } & $(0001)$ & $(11 \overline{2} 0)_{\mathrm{Ti}}$ & $(11 \overline{2} 0)_{\mathrm{Ti}-\mathrm{Al}}$ & $(1 \overline{1} 00)_{\mathrm{Ti}-1}$ & $(1 \overline{1} 00)_{\mathrm{Ti}-2}$ & $(1 \overline{1} 00)_{\mathrm{TiAl}-1}$ & $(1 \overline{1} 00)_{\mathrm{TiAl}-2}$ \\
\hline$\Delta d_{12}, \%$ & -5.3 & -8.2 & -3.6 & -15.5 & -8.5 & 2.2 & -12.4 \\
$\Delta d_{23}, \%$ & 1.0 & -1.2 & 2.1 & -2.1 & -4.5 & 0.7 & 5.7 \\
$\Delta d_{34}, \%$ & -1.8 & 1.7 & 0.3 & 2.6 & -0.7 & -1.6 & 2.4 \\
$\varepsilon, \AA$ & 0.19 & 0.07 & 0.03 & 0.22 & -0.03 & -0.07 & 0.10
\end{tabular}

Примечание. Отрицательное значение $\varepsilon$ означает, что атом титана лежит выше, чем атом алюминия.

Расчеты поверхностной энергии проводились по стандартной формуле

$$
\begin{aligned}
\sigma= & \frac{1}{2 S}\left[E_{\mathrm{tot}}^{\mathrm{slab}}-N_{\mathrm{Ti}} \mu_{\mathrm{Ti}_{3} \mathrm{Al}}-\mu_{\mathrm{Al}}^{\text {bulk }}\left(3 N_{\mathrm{Al}}-N_{\mathrm{Ti}}\right)\right. \\
& \left.-\Delta \mu_{\mathrm{Al}}\left(3 N_{\mathrm{Al}}-N_{\mathrm{Ti}}\right)\right]
\end{aligned}
$$

где $N_{\mathrm{Ti}}$ и $N_{\mathrm{Al}}$ - число атомов титана и алюминия в пленке сплава, $\mu_{\mathrm{Ti}_{3} \mathrm{Al}}-$ химический потенциал объемного сплава, а $\Delta \mu_{\mathrm{Al}}$ - отклонение химического потенциала алюминия на поверхности $\mathrm{Ti}_{3} \mathrm{Al}$ от его значения в объемном алюминии $\left(\mu_{\mathrm{Al}}^{\mathrm{bulk}}\right)$, которое может изменяться в интервале $-\Delta H \leq \Delta \mu_{\mathrm{Al}} \leq 0$, где $\Delta H-$ энтальпия образования $\mathrm{Ti}_{3} \mathrm{Al}$, равная $1.125 \mathrm{eV}$. Рассчитанное значение $\Delta H$ хорошо согласуется с экспериментальными $(1.00-1.16 \mathrm{eV}$ [41-43]) и теоретическими (1.13 [18] и $1.160 \mathrm{eV}$ [20]) значениями. Больше деталей расчета поверхностной энергии приведено в наших ранних работах $[15,16]$.

На рис. 3 представлена рассчитанная диаграмма стабильности низкоиндексных поверхностей сплава $\mathrm{Ti}_{3} \mathrm{Al}$. Видно, что в Al-обогащенной области стабильной является поверхность $(11 \overline{2} 0)_{\mathrm{Ti}-\mathrm{Al}}$ со смешанным окончанием, тогда как поверхность $(1 \overline{1} 00)_{\text {Ti-Al-1 }}$ со смешанным

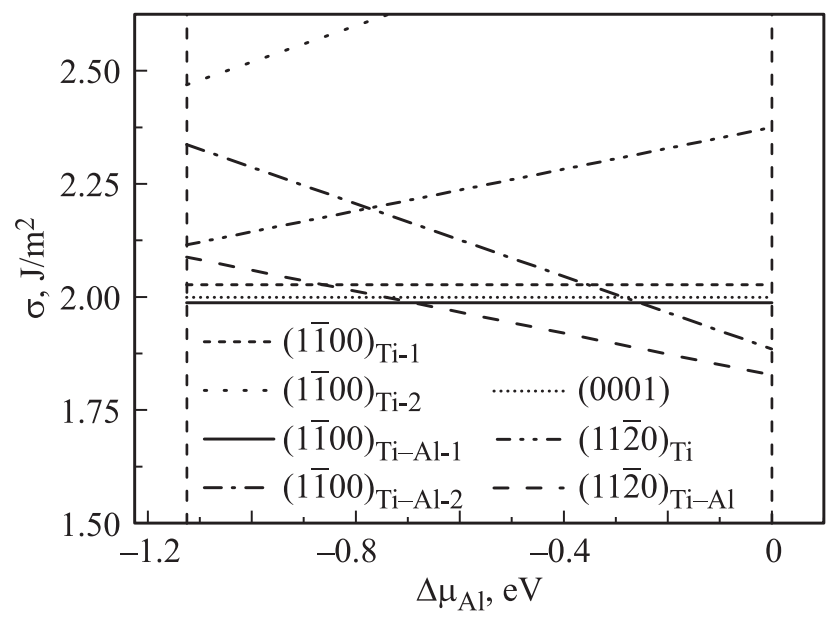

Рис. 3. Зависимость поверхностных энергий низкоиндексных поверхностей сплава $\mathrm{Ti}_{3} \mathrm{Al}$ от химического потенциала алюминия. окончанием более стабильна в Ті-обогащенном пределе. Разница в поверхностных энергиях этой структуры и базальной стехиометрической поверхности (0001) минимальна и составляет $0.012 \mathrm{~J} / \mathrm{m}^{2}$. Большая стабильность поверхностей, верхний слой которых содержит атомы алюминия, согласуется с выявленными ранее тенденциями для сплавов $\mathrm{TiAl}$ и $\mathrm{TiAl}_{3}[11,12,14-17]$. Рассчитанная поверхностная энергия базальной плоскости (0001) равна $1.987 \mathrm{~J} / \mathrm{m}^{2}$, что хорошо согласуется с результатами ранних работ: 1.964 [44] и $2.02 \mathrm{~J} / \mathrm{m}^{2}$ [39]. Энергии других поверхностей ранее не рассчитывались.

В табл. 2 приведены релаксации трех первых межслоевых расстояний, а также расщепление ближайшего к поверхности смешанного слоя: первого слоя в случае (0001), (11 $\overline{2} 0)_{\mathrm{Ti}-\mathrm{Al}}, \quad(1 \overline{1} 00)_{\mathrm{Ti}-\mathrm{Al}-1}$ и $(1 \overline{1} 00)_{\mathrm{Ti}-\mathrm{Al}-2}$, второго слоя для $(11 \overline{2} 0)_{\mathrm{Ti}}$ и $(1 \overline{1} 00)_{\mathrm{Ti}-1}$, а также третьего слоя для поверхности $(1 \overline{1} 00)_{\mathrm{Ti}-2}$. Отметим, что релаксация межслоевых расстояний оценивалась по формуле $\Delta d_{i j}=\left(d_{i j}-d_{0}\right) / d_{0}$, где $d_{0}-$ межплоскостное расстояние в объеме, а $i, j-$ номера соответствующих атомных слоев. Поскольку в смешанных слоях атомы титана и алюминия незначительно смещены, для оценки релаксации использовалось их среднее положение. Видно, что среди рассмотренных поверхностей с одинаковой ориентацией те, которые имеют наименышую поверхностную энергию, характеризуются также и наименьшей релаксацией межслоевых расстояний.

3.3. Адсорбция кислорода на низкоиндексных поверхностях сплава $\mathrm{Ti}_{3} \mathrm{Al}$.

3.3.1. Пове рхность (0001). Прежде всего обсудим адсорбцию кислорода на базальной плоскости (0001), поскольку имеются теоретические данные [19,20], позволяющие провести сопоставление результатов. Кроме того, это единственная поверхность, атомные слои которой имеют стехиометрический состав, и, согласно результатам, полученным в работе [18], ее энергия понижается при сегрегации алюминия к поверхности. На рис. 4, $а$ показаны позиции, в которых изучалась адсорбция кислорода на поверхности (0001). Используя обозначения, введенные в ранних работах [15-17], будем обозначать вершинные позиции над атомами поверхностного слоя буквой $T$, позиции в центре треугольников, образованных поверхностными атомами, расположенными над атомами подповерхностного слоя, - 

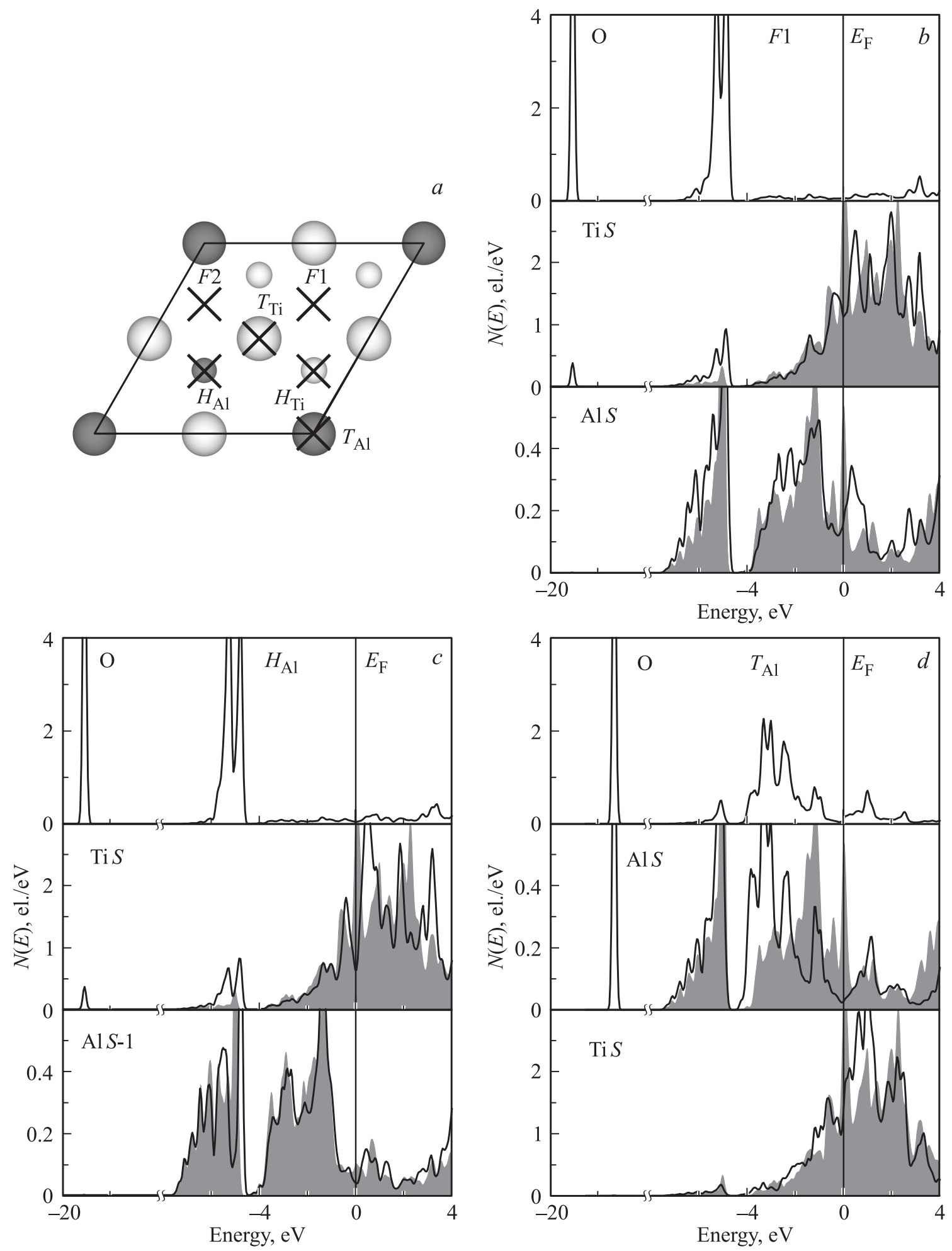

Рис. 4. Позиции адсорбции кислорода на стехиометрической поверхности $(0001)(a)$, а также локальные ПЭС кислорода и ближайших к нему атомов поверхностного $(S)$ и подповерхностного $(S-1)$ слоев для позиций $F 1(b), H_{\mathrm{Al}}(c)$ и $T_{\mathrm{Al}}(d)$. Локальные ПЭС атомов $\mathrm{Ti}$ и $\mathrm{Al}$ на чистой поверхности показаны серым цветом. Обозначение атомов Ti и Al такое же, как на рис. 1. Атомы поверхностного и подповерхностного слоев показаны большими и маленькими шарами соответственно.

$H$, а те позиции, под которыми отсутствуют атомы подложки, будем обозначать как $F$-позиции. Отметим, что в $H$ - и $F$-позициях адатом кислорода трехкратно координирован поверхностными атомами. Как видно из табл. 3, в которой приведены рассчитанные энергии адсорбции, наиболее предпочтительной является 
Таблица 3. Энергия адсорбции кислорода $E_{\text {ads }}$ на поверхности $\mathrm{Ti}_{3} \mathrm{Al}(0001)$, расстояние между кислородом и ближайшими атомами подложки, $d(\mathrm{O}-\mathrm{Me})$, а также положение кислорода $h_{0}$ относительно поверхностного слоя (в скобках приведены значения из работы [20])

\begin{tabular}{c|c|c|c|c|c|c}
\hline \multirow{2}{*}{ Параметр } & \multicolumn{7}{|c}{ Позиция } \\
\cline { 2 - 7 } & $F 1$ & $F 2$ & $H_{\mathrm{Ti}}$ & $H_{\mathrm{Al}}$ & $T_{\mathrm{Ti}}$ & $T_{\mathrm{Al}}$ \\
\hline$E_{\mathrm{ads}}, \mathrm{eV}$ & 6.64 & 5.70 & 5.61 & 6.51 & 4.01 & 2.88 \\
$E_{b}, \mathrm{eV}$ & $9.19(10.87)$ & $8.26(9.89)$ & $8.17(9.81)$ & $9.07(10.77)$ & 6.57 & $5.44(7.03)$ \\
$d(\mathrm{O}-\mathrm{Ti}), \AA$ & $1.95(1.94)$ & $1.94(1.92)$ & $1.95(1.93)$ & $1.96(1.94)$ & 1.74 & 3.26 \\
$d(\mathrm{O}-\mathrm{Al}), \AA$ & 3.51 & $1.94(1.96)$ & $1.92(1.95)$ & 3.33 & 3.36 & $1.71(1.71)$ \\
$h_{0}, \AA$ & $0.99(1.01)$ & $1.06(1.12)$ & $0.96(1.05)$ & $1.00(1.03)$ & 1.69 & $1.51(1.55)$
\end{tabular}

$F 1$-позиция, в которой кислород взаимодействует с тремя поверхностными атомами титана. В этом случае длина связи О-Ті составляет $1.95 \AA ̊$. . Напомним, что в $\mathrm{TiO}_{2}$ со структурой рутила длина связи кислорода с титаном равна $1.96 \AA$. Энергия адсорбции в $H_{\mathrm{Al}}$-позиции лишь незначительно меньше (табл. 3 ), чем в $F 1$-позиции. В $H_{\mathrm{Al}}$-позиции атом кислорода также взаимодействует с тремя поверхностными атомами титана, при этом длина связи О-Ті равна $1.96 \AA$. Кислород в этой позиции расположен над подповерхностным атомом алюминия, но расстояние между ними значительно больше, чем сумма ковалентных радиусов. В этом случае кислород взаимодействует с атомом алюминия не напрямую, а через гибридизацию $\mathrm{Al} s, p$-орбиталей с $s, d$-орбиталями

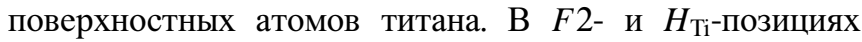
появление алюминия в ближайших соседях уменьшает энергию адсорбции на $\sim 0.9 \mathrm{eV}$. Последнее обусловлено тем фактом, что вклад от гибридизации О $p$-орбиталей c Al $s, p$-орбиталями в энергетику связи существенно меньше, чем от гибридизации состояний кислорода с состояниями переходного металла. Наименьшие энергии адсорбции получены в вершинных $T_{\mathrm{Al}}$ и $T_{\mathrm{Ti}}$-позициях,

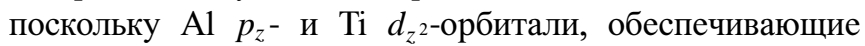
взаимодействие с кислородом в данных позициях, практически не заполнены. В связи с этим взаимодействие кислорода с поверхностью в вершинных позициях менее выгодно, что и отражают полученные значения энергий адсорбции (табл. 3). Отметим, что предпочтительность обогащенных титаном позиций для адсорбции кислорода была также установлена в наших ранних работах [15-17] для сплавов $\mathrm{TiAl}$ и $\mathrm{TiAl}_{3}$.

Адсорбция кислорода существенно влияет на атомную структуру поверхности сплава. Практически во всех ямочных $(F$ и $H)$ позициях наблюдается увеличение первого межслоевого расстояния $\left(d_{12}\right)$ на $0.4-3.3 \%$, тогда как для чистой поверхности характерно его сжатие на $5.3 \%$. Отметим, что в вершинной $T_{\mathrm{Al}}$-позиции отрицательная релаксация поверхности не снимается, a, напротив, сжатие первого межслоевого расстояния увеличивается до 5.6\%. В целом релаксация следующих межслоевых расстояний изменяется несущественно.

Поскольку в [20] были приведены значения энергии связи, для сопоставления результатов в табл. 3 также представлены эти энергии, рассчитанные с использованием спин-поляризованного значения энергии атома кислорода. Видно, что тенденции в энергетике связи кислорода с поверхностью (0001) совпадают в обеих работах, хотя сами значения $E_{b}$ существенно различаются. Отметим, что, например, в $F 1$-позиции разность полных энергий поверхности с кислородом и чистой поверхности равна $-10.75 \mathrm{eV}$, что хорошо согласуется со значением $-10.87 \mathrm{eV}$, приведенным в работе [20] в качестве энергии связи. Это позволяет предположить, что в [20] использовалось значение энергии атома кислорода, полученное в расчетах не спин-поляризованным методом. В этом случае энергия атома кислорода очень мала и ею можно пренебречь.

Объяснить предпочтительность конкретных позиций для адсорбции кислорода на низкоиндексных поверхностях сплава $\mathrm{Ti}_{3} \mathrm{Al}$ можно на основе анализа электронных характеристик. На рис. 4, $b-d$ приведены локальные плотности электронных состояний (ПЭС) кислорода и ближайших к нему металлических атомов для позиций $F 1, H_{\mathrm{Al}}$ и $T_{\mathrm{Al}}$. Поскольку кислород преимущественно взаимодействует с металлическими атомами поверхностного слоя, это приводит к появлению пиков на локальных ПЭС Ті и Al, которые совпадают по энергетическому положению с соответствующими пиками О $s, p$-зон. Видно, что в наиболее энергетически предпочтительной $F 1$-позиции $p$-зона кислорода имеет два узких пика, расположенных при энергиях -5.2 и $-4.7 \mathrm{eV}$. При этих же энергиях расположены состояния титана, которые отщепляются от дна валентной зоны металла вследствие его взаимодействия с $p$-состояниями кислорода, и формируется псевдощель между титановыми состояниями при энергии $-4 \mathrm{eV}$ (рис. $4, b)$. Имеется также небольшой пик ПЭС титана, локализованный при энергиях $-19.1 \mathrm{eV}$, обусловленный гибридизацией его состояний с $s$-состояниями кислорода. Отметим, что резкий пик, соответствующий О $s$-зоне, находится при энергиях от -19.5 до $-17 \mathrm{eV}$ в зависимости от позиции адсорбции кислорода на поверхности сплава. Локальные ПЭС поверхностного атома алюминия также изменяются, но это обусловлено не прямым взаимодействием с алюминием, поскольку межатомное расстояние $\mathrm{O}-\mathrm{Al}$ равно $3.51 \AA$, а гибри- 
дизацией $\mathrm{Al} s, p$-орбиталей с $s, d$-орбиталями атомов титана, с которыми непосредственно связан кислород на поверхности. Оценка зарядового переноса по методу Бадера [45] показала, что при адсорбции в $F 1$-позиции к адатому кислорода приходит заряд, равный $1.09 e$, при этом ближайшие к кислороду атомы титана теряют по $\sim 0.38 e$. В целом появление новых пиков, изменение структуры кривых ПЭС поверхностных и подповерхностных металлических атомов, а также их смещение в сторону отрицательных энергий относительно ПЭС атомов на чистой поверхности, расщепление низколежащих состояний указывают на формирование новых связей металлов с кислородом и ослабление металлических связей между атомами поверхностных слоев. Особенно сильно изменяются ПЭС тех атомов, которые непосредственно вовлечены во взаимодействие с кислородом. Такое поведение является типичным и для других позиций адсорбции.

Структура ПЭС кислорода при его адсорбции в $H_{\mathrm{Al}}$-позиции изменяется незначительно. Отличие заключается в более сильном расщеплении р-зоны кислорода: соответствующие пики лежат при энергиях -5.3 и $-4.8 \mathrm{eV}$ (рис. 4, c). Зарядовый перенос к адсорбированному атому кислорода в этом случае практически такой же, как в $F 1$-позиции. Однако в отличие от $F 1$-позиции центр тяжести $\mathrm{O} s$-зоны в $H_{\mathrm{Al}}$-позиции на $0.1 \mathrm{eV}$ смещен к уровню Ферми, что может указывать на меньшую энергетику связи кислорода (на $0.13 \mathrm{eV}$ ) в данной позиции. Кроме того, длина связи О-Ті также на $0.01 \AA$ больше в $H_{\mathrm{Al}}$-позиции, чем в $F 1$-позиции. Отметим, что соответствующие кривые ПЭС металлических атомов в $H_{\mathrm{Al}}$-позиции изменяются так же, как было описано выше. Кроме того, на рис. 4, с приведены ПЭС подповерхностного атома алюминия, которые изменяются в меньшей степени, чем ПЭС поверхностных атомов алюминия. Поскольку их изменение подобно представленному на рис. $4, b$, они не приводятся.

Ситуация принципиально иная, когда атом кислорода адсорбируется в вершинной $T_{\mathrm{Al}}$-Позиции над атомом алюминия. Из рис. $4, d$ видно, что обе $s$ - и $p$-зоны кислорода существенно смещаются к уровню Ферми, при этом резкий пик $s$-зоны находится значительно выше при энергии $(-17.3 \mathrm{eV})$, чем в двух других позициях. При этой же энергии расположен индуцированный взаимодействием с кислородом резкий пик $s$-состояний алюминия. Поскольку на чистой поверхности валентная зона алюминия расщеплена на $s$ - и $p$-зону, вследствие взаимодействия $p$-зона кислорода также расщепляется на две подзоны. Первая небольшая подзона расположена в области от -6.2 до $-4.8 \mathrm{eV}$, а вторая находится при энергиях выше $-4.1 \mathrm{eV}$. Видно, что положение всех пиков $\mathrm{O} p$-зоны совпадает с соответствующими пиками $\mathrm{Al} p$-состояний. Поскольку поверхностные атомы титана находятся на расстоянии $3.26 \AA$ от адатома кислорода, их ПЭС изменяются лишь незначительно: в интервале энергий от -1.3 до $-0.8 \mathrm{eV}$ появляются дополнительные состояния, обусловленные гибридизацией Тi $s, d$-состояний с Al $p$-состояниями. Таким образом, в данной вершинной позиции кислород в основном взаимодействует с $p$-состояниями поверхностного алюминия, при этом центр тяжести р-зоны смещается на $\sim 1 \mathrm{eV}$ от уровня Ферми.

Изменение локальных ПЭС поверхностных атомов при адсорбции кислорода в других ямочных позициях подобно описанному выше для $F 1-$ и $H_{\mathrm{Al}}$-позиций. В отличие от случая адсорбции кислорода на поверхностях сплавов с большим содержанием алюминия [10,11,13-17] энергия адсорбции на поверхности $\mathrm{Ti}_{3} \mathrm{Al}(0001)$ в меньшей степени зависит от позиции адатома кислорода. Разброс в энергиях связи для четырех ямочных позиций составляет лишь $\sim 1 \mathrm{eV}$, a бо́льшая энергия адсорбции в $T_{\mathrm{Ti}}$-позиции, чем в $T_{\mathrm{Al}}$-позиции, может быть объяснена большей гибридизацией $p$-орбиталей кислорода с $d$-орбиталями атома переходного элемента. Именно этот фактор вследствие повышения концентрации титана на поверхности (0001) приводит к повышению энергетики связи кислорода на данной поверхности по сравнению с таковой на стехиометрических поверхностях сплавов $\mathrm{TiAl}$ и $\mathrm{TiAl}_{3}$.

3.3.2. Поверхность (1120). На рис. $2, b$ приведена атомная структура поверхности $\mathrm{Ti}_{3} \mathrm{Al}(11 \overline{2} 0)_{\mathrm{Ti}-\mathrm{Al}}$ со смешанным окончанием, для которой найдено, что она является стабильной в обогащенной алюминием области. Прежде всего несколько слов необходимо сказать о плотности упаковки всех трех рассмотренных поверхностей. В случае поверхности (0001) плотность упаковки равна $0.140 \AA^{-2}$, тогда для поверхностей $(11 \overline{2} 0)$ и (1100) она значительно меньше и составляет 0.087 и $0.075 \AA^{-2}$ соответственно. Обычно более плотно упакованные поверхности характеризуются более низкой поверхностной энергией, тогда как в данном случае определяющим оказался химический состав поверхностного слоя, а именно большее содержание атомов алюминия в этом слое. В работе [18] также отмечалось, что повышение концентрации алюминия на поверхности сплава понижает поверхностную энергию.

Из рис. 5, $a$ видно, что на поверхности (112̄0) имеется большее число неэквивалентных позиций, которые необходимо рассматривать при изучении адсорбции кислорода. Кроме упомянутых ранее ямочных и вершин-

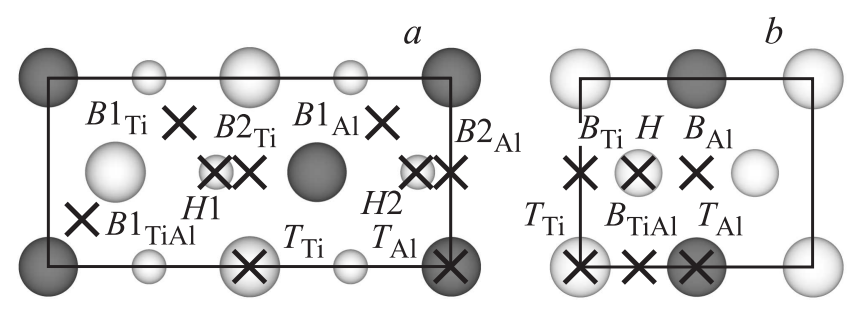

Рис. 5. Позиции адсорбции кислорода на поверхностях $(11 \overline{2} 0)_{\mathrm{Ti}-\mathrm{Al}}(a)$ и $(1 \overline{1} 00)_{\mathrm{Ti}-\mathrm{Al}-1}(b)$ со смешанным окончанием. Обозначение атомов $\mathrm{Ti}$ и $\mathrm{Al}$ такое же, как на рис. $4, a$. 
Таблица 4. Энергия адсорбции кислорода $E_{\text {ads }}$ на поверхности $\mathrm{Ti}_{3} \mathrm{Al}(11 \overline{2} 0)_{\mathrm{Ti}-\mathrm{Al}}$, расстояние между кислородом и атомами подложки $d(\mathrm{O}-\mathrm{Me})$, а также положение кислорода $h_{0}$ относительно поверхностного слоя

\begin{tabular}{c|c|c|c|c|c|c|c|c}
\hline \multirow{2}{*}{ Параметр } & \multicolumn{9}{|c}{ Позиция } \\
\cline { 2 - 9 } & $H 1$ & $B 1_{\mathrm{Ti}}$ & $B 1_{\mathrm{Al}}$ & $B 1_{\mathrm{TiAl}}$ & $B 2_{\mathrm{Ti}}$ & $B 2_{\mathrm{Al}}$ & $T_{\mathrm{Ti}}$ & $T_{\mathrm{Al}}$ \\
\hline$E_{\text {ads }}, \mathrm{eV}$ & 5.58 & 5.41 & 5.17 & 5.39 & 5.50 & 5.10 & 3.90 & 2.46 \\
$d(\mathrm{O}-\mathrm{Ti}), \AA$ & $1.98,2.07^{*}$ & $1.86,3.30^{*}$ & $3.89,2.04^{*}$ & $1.93,2.06^{*}$ & $2.35,2.05^{*}$ & $1.91,1.98^{*}$ & $1.69,4.15^{*}$ & $3.35,3.90^{*}$ \\
$d(\mathrm{O}-\mathrm{Al}), \AA$ & 2.65 & 3.81 & 1.97 & 1.85 & 1.89 & 2.39 & 3.70 & 1.67 \\
$h_{0}, \AA$ & 0.44 & 1.17 & 0.07 & 0.52 & 0.40 & 0.50 & 1.69 & 1.54
\end{tabular}

* Расстояние от адатома кислорода до атомов подповерхностного слоя.

ных позиций имеются также стабильные мостиковые $B$-позиции между двумя поверхностными атомами. Наибольшая энергия адсорбции кислорода на данной поверхности составляет $5.58 \mathrm{eV}$ (табл. 4) и соответствует $H 1$-позиции в титановом треугольнике над подповерхностным атомом титана. Адсорбция кислорода в этой позиции приводит к смещению ближайших поверхностных атомов титана на $0.10-0.12 \AA$ в сторону вакуума, а атома алюминия, который находится на расстоянии $2.65 \AA$, - на $0.05 \AA$. Длины связи кислорода с двумя поверхностными атомами титана на $0.42 \AA$ больше, чем с ближайшим поверхностным атомом титана (1.98 $\AA$ ), тогда как расстояние до подповерхностного атома титана равно $2.07 \AA$. Очевидно, что взаимодействие кислорода с последними атомами сильнее, чем с двумя другими.

При адсорбции кислорода в $B 2_{\text {Ti-Позиции длинного }}$ моста кислород сильнее связан с подповерхностным атомом титана $(2.05 \AA)$ и поверхностным алюминием $(1.89 \AA)$, чем с двумя атомами титана в поверхностном слое $(2.35 \AA)$. Именно этим структурным фактором обусловлено меньшее значение энергии адсорбции кис-

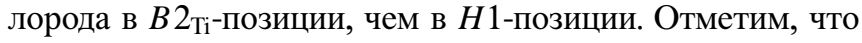
$H 2$-позиция, в которой кислород находится в центре алюминиевого треугольника над атомом титана второго слоя, является нестабильной, поскольку в процессе релаксации кислород из этой позиции смещается в мостиковую $B 2_{\mathrm{Al}}$-позицию. В последнем случае расстояние до ближайшего поверхностного атома титана $(1.91 \AA)$ лишь на $0.07 \AA$ меньше, чем до подповерхностного титана, но существенно меньше, чем до поверхностных атомов алюминия $(2.39 \AA)$. Длина связей О-Ті в этом случае меньше, чем при адсорбции кислорода в $H 1$ -

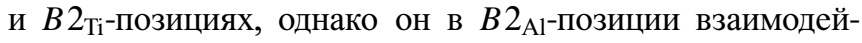
ствует с меньшим числом атомов титана, чем и обусловлена меньшая энергия связи. Как и на поверхности $\mathrm{Ti}_{3} \mathrm{Al}(0001)$, наименьшая энергия адсорбции найдена в вершинной $T_{\mathrm{Al}}$-позиции. Межатомные $(\mathrm{O}-\mathrm{Me})$ расстояния для всех позиций приведены в табл. 4.

Как видно из рис. 6, $a, e$, несмотря на небольшую разницу в энергиях адсорбции кислорода в $H 1-$ и

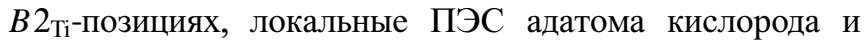
атомов поверхности демонстрируют различный механизм химической связи кислорода с поверхностью. ПЭС поверхностных атомов титана при адсорбции кислоро- да в H1-позиции изменяются так же, как отмечалось ранее для ямочных позиций: появляются отщепленные от дна валентной зоны титана низколежащие состояния, обусловленные взаимодействием с $s$ - и $p$-зонами кислорода (рис. 6,a), при этом даже на кривых ПЭС, соответствующих более удаленным от кислорода атомам титана. Хотя расстояние $\mathrm{O}-\mathrm{Al}$ на $0.74 \AA$ превосходит сумму ковалентных радиусов кислорода и алюминия, ПЭС поверхностного атома алюминия изменяются также существенно. Однако эти изменения затрагивают в большей степени $s$-состояния алюминия, при этом резкий пик, расположенный ниже $-5 \mathrm{eV}$, характерный для чистой поверхности, расщепляется на два, что хорошо видно из рис. $6, b$. Отметим, что подобное поведение наблюдается при взаимодействии водорода с примесными атомами бора, алюминия или галлия в сплавах [46] и на их границах зерен [47]. В упомянутых выше работах это объяснялось принципом запрета Паули, поскольку имеет место гибридизация $s^{2}$-состояний примеси и $s^{1}$-состояния водорода, что приводит к образованию антисвязующих состояний (дополнительный пик ПЭС при несколько бо́льших энергиях, чем первый пик) и взаимному отталкиванию между атомами. Гибридизация $2 s^{2}$-состояний кислорода с $3 s$-состояниями алюминия может также приводить к подобному эффекту. В пользу этого аргумента свидетельствует тот факт, что атом алюминия испытывает латеральное смещение (на $\sim 0.1 \AA)$ в сторону от адатома кислорода в H1-позиции по сравнению с его положением в случае чистой поверхности. Кроме того, как видно из рис. $6, c, d$, локализация состояний низкоэнергетического пика явно указывает на их связующую природу, тогда как более высокоэнергетические состояния не вносят вклада в связь кислорода с алюминием. В целом сильное взаимодействие $2 p$-орбиталей кислорода с $s, d$-орбиталями трех поверхностных и одного подповерхностного атома титана обусловливает максимальную энергию адсорбции в $H 1$-позиции.

При адсорбции кислорода в $B 2_{\mathrm{Ti}}$-позиции (рис. $6, e$ ) Al p-состояния также претерпевают значительные изменения, при этом тонкая структура ПЭС в интервале энергий от -7.3 до $-4.5 \mathrm{eV}$ хорошо согласуется со структурой $p$-зоны кислорода. Кроме того, резкий пик при энергии $-4.6 \mathrm{eV}$ на ПЭС алюминия в случае чистой 


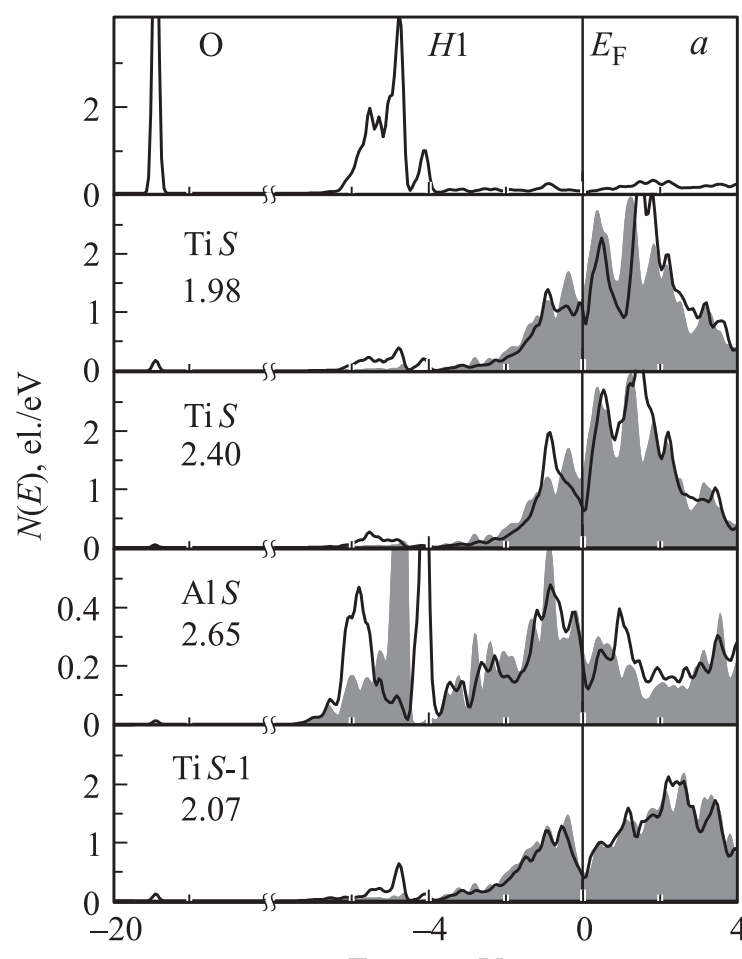

Energy, eV

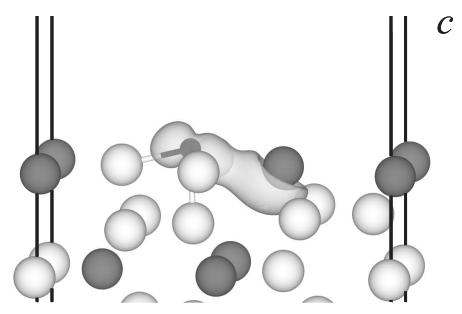

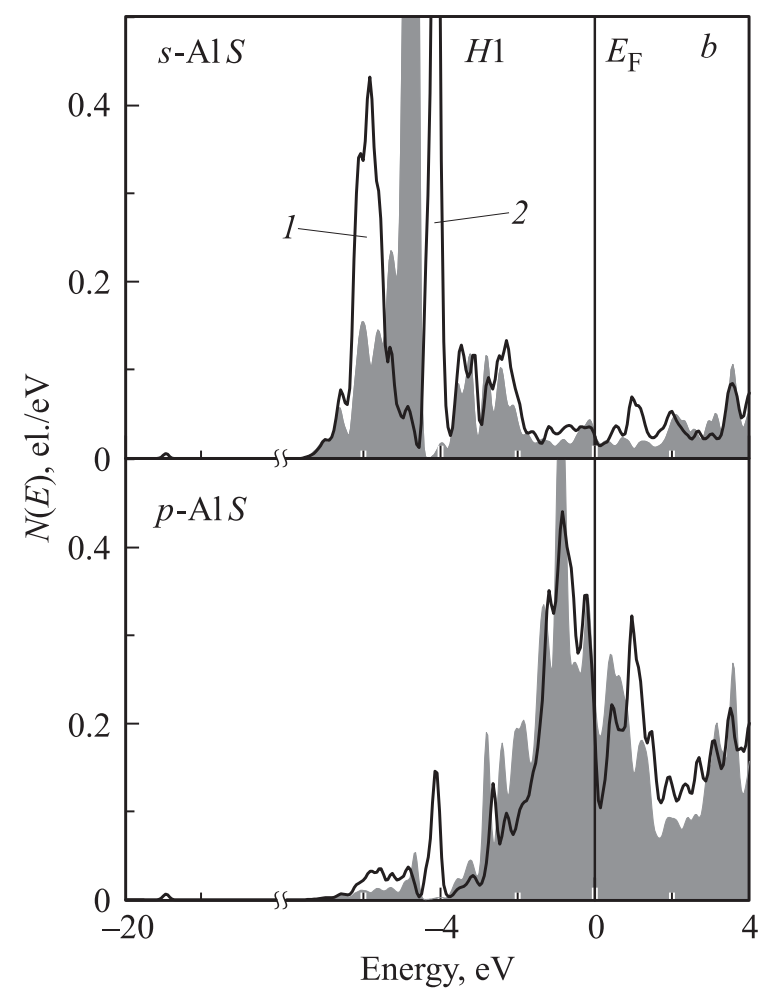

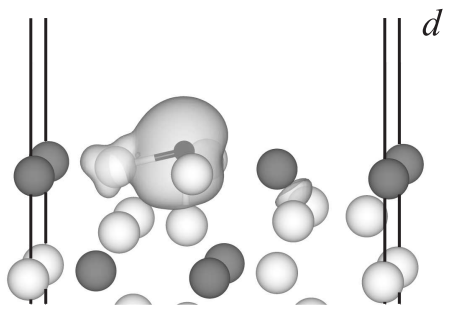

Рис. 6. Локальные плотности электронных состояний кислорода и ближайших к нему атомов поверхностного $(S)$ или подповерхностного $(S-1)$ слоя при адсорбции кислорода в позициях $H 1(a)$ и $B 2_{\mathrm{Ti}}(e)$ на поверхности $\mathrm{Ti}_{3} \mathrm{Al}(11 \overline{2} 0)_{\mathrm{Ti}-\mathrm{Al}}, \mathrm{a}$ также парциальные ПЭС поверхностного атома алюминия $(b, f)$ для этих же позиций адсорбции кислорода. Соответствующие ПЭС атомов чистой поверхности показаны серым цветом. Числа на частях $a$ и $e-$ длины связей О-Me (в $\AA$ ). Локализация состояний, отмеченных цифрами 1 и 2 на частях $b, f$, показана на частях $c, g$ и $d, h$ соответственно.

поверхности смещается на $1.7 \mathrm{eV}$ в сторону отрицательных энергий при взаимодействии с кислородом. Отметим также пик, центрированный при энергии $-3.8 \mathrm{eV}$, который появляется вследствие уменьшения числа состояний вблизи энергии Ферми. Низкоэнергетический пик, расположенный существенно ниже $(-19.3 \mathrm{eV})$, обусловлен взаимодействием $\mathrm{Al} s, p$-состояний с $s$-зоной кислорода (рис. $6, f$ ). Отметим, что пик $s$-состояний алюминия при энергии $-6.3 \mathrm{eV}$ (обозначен цифрой 1 на рис. $6, f)$ имеет практически такую же локализацию, как и соответствующий пик при адсорбции кислорода в H1-позиции. В то же время резкие пики $\mathrm{Al}$ $s, p$-состояний (обозначены цифрой 2 на рис. $6, f$ ) при энергии $-3.8 \mathrm{eV}$ обусловлены также гибридизацией с $\mathrm{O}$ $p$-состояниями. В этом случае поверхностный атом алюминия не испытывает латерального смещения. Как видно из рис. $6, h$, локализация состояний, расположенных в этом энергетическом интервале (от -4.2 до $-3.4 \mathrm{eV}$ ) (рис. $6, f)$ соответствует преимущественно $p_{z}$-орбиталям кислорода.

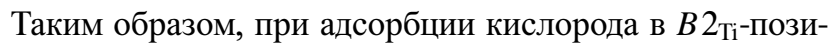
ции вклады подповерхностного атома титана и поверхностного алюминия не полностью компенсируют уменьшение в энергетике связи кислорода с атомами титана поверхностного слоя вследствие увеличения расстояния между ними. Изменение кривых ПЭС при адсорбции в вершинных позициях подобно отмеченному ранее на поверхности (0001) и поэтому не обсуждается. В целом на поверхности $\mathrm{Ti}_{3} \mathrm{Al}(11 \overline{2} 0)_{\mathrm{Ti}}$ Al разброс в энергиях адсорбции еще меньше $(\sim 0.5 \mathrm{eV})$, чем на поверхности (0001), и указывает на уменьшение селективности взаимодействия кислорода на поверхности.

3.3.3. Поверхность (1100). На поверхности $(1 \overline{1} 00)_{\mathrm{Ti}-\mathrm{Al}-1}$ адсорбция кислорода рассматривалась в позициях, представленных на рис. $5, b$. Оказалось, что ямочная $H$-позиция в центре прямоугольника с равным 


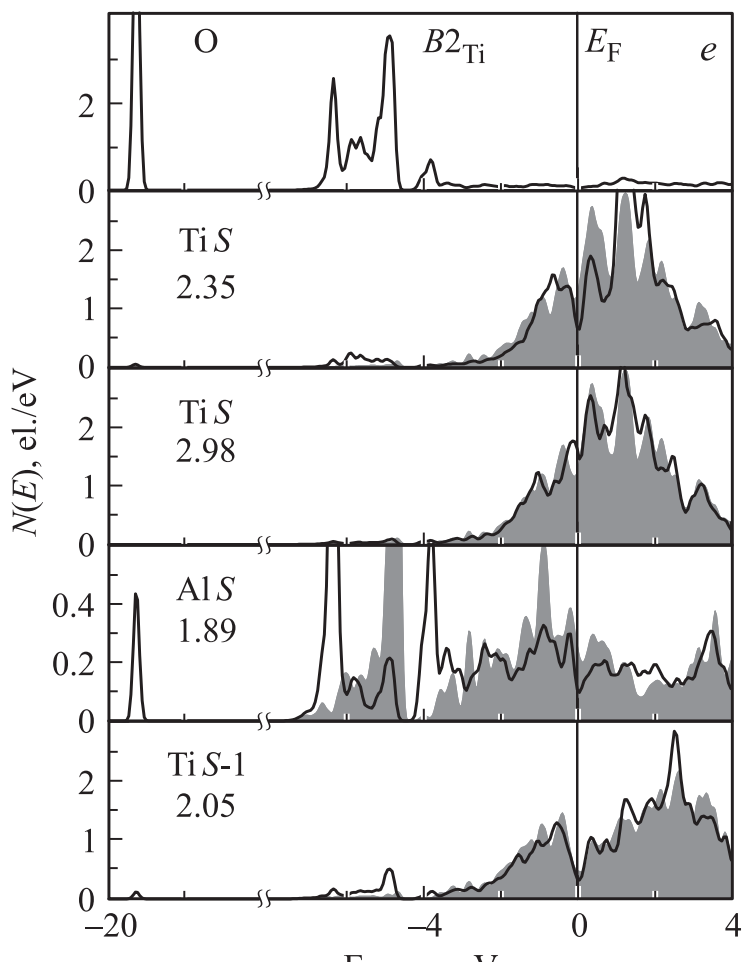

Energy, eV

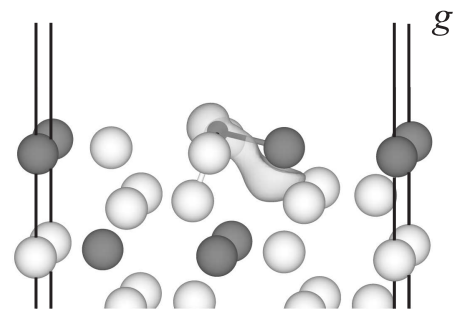

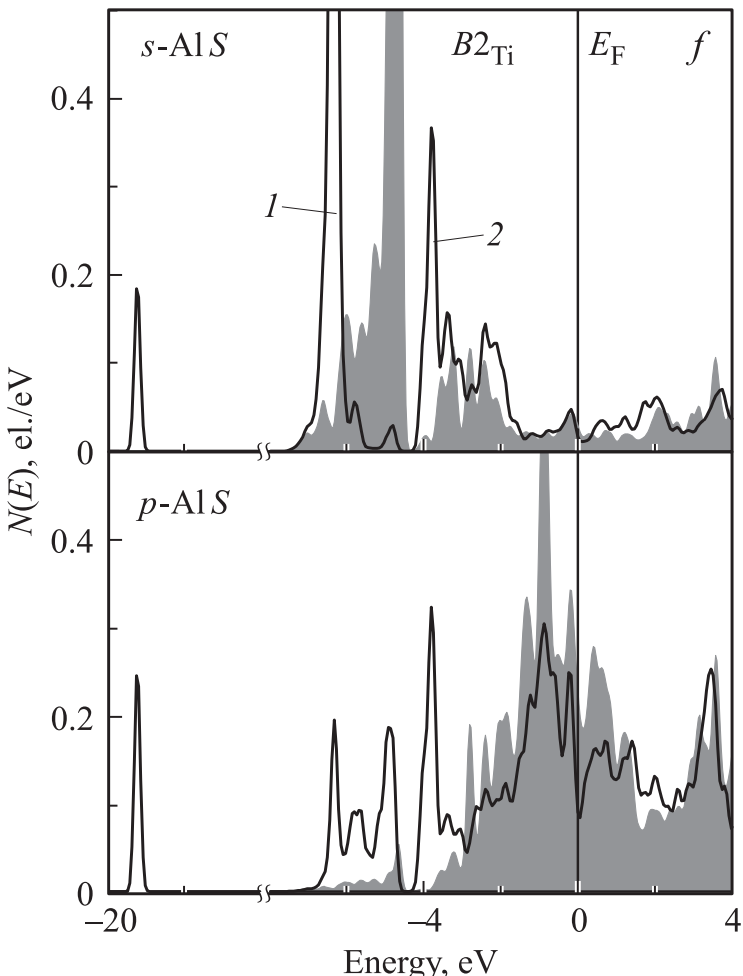

Energy, eV

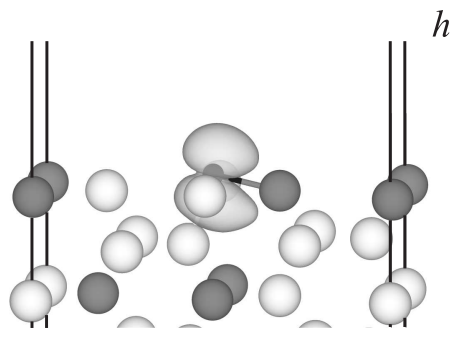

Рис. 6 (продолждение).

составом титана и алюминия над подповерхностным атомом титана не является стабильной, поскольку кислород

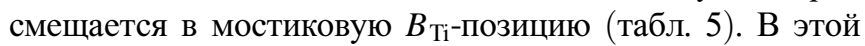

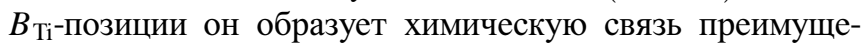
ственно с двумя атомами титана подповерхностного слоя, расстояние до которых на $0.4 \AA$ меньше, чем до атомов титана поверхностного слоя. Данный вывод подтверждают расчеты локальных ПЭС поверхностных и подповерхностных атомов титана (рис. 7,a). Видно, что электронная структура подповерхностных атомов титана при адсорбции кислорода изменяется сильнее, чем атомов поверхностного слоя: структура низколежащих пиков ПЭС атомов титана в первом случае более выражена и большее число состояний отщепляется от

Таблица 5. Энергия адсорбции кислорода $E_{\text {ads }}$ на поверхности $\mathrm{Ti}_{3} \mathrm{Al}(1 \overline{1} 00)_{\mathrm{Ti}-\mathrm{Al}-1}$, расстояние между кислородом и атомами подложки $d(\mathrm{O}-\mathrm{Me})$, а также положение кислорода $h_{0}$ относительно поверхностного слоя

\begin{tabular}{c|c|c|c|c|c}
\hline \multirow{2}{*}{ Параметр } & \multicolumn{5}{|c}{ Позиция } \\
\cline { 2 - 6 } & $B_{\mathrm{Ti}}$ & $B_{\mathrm{Al}}$ & $B_{\mathrm{TiAl}}$ & $T_{\mathrm{Ti}}$ & $T_{\mathrm{Al}}$ \\
\hline$E_{\mathrm{ads}}, \mathrm{eV}$ & 6.41 & 4.70 & 4.84 & 3.50 & 2.57 \\
$d(\mathrm{O}-\mathrm{Ti}), \AA$ & $2.33,1.93^{*}$ & $3.73,1.92^{*}$ & $1.84,3.25^{*}$ & $1.69,3.90^{*}$ & $3.15,3.77^{*}$ \\
$d(\mathrm{O}-\mathrm{Al}), \AA$ & 3.72 & 2.35 & 1.79 & 3.44 & 1.68 \\
$h_{0}, \AA$ & 0.24 & 0.37 & 1.08 & 1.69 & 1.31
\end{tabular}

* Расстояние от адатома кислорода до атомов подповерхностного слоя. 

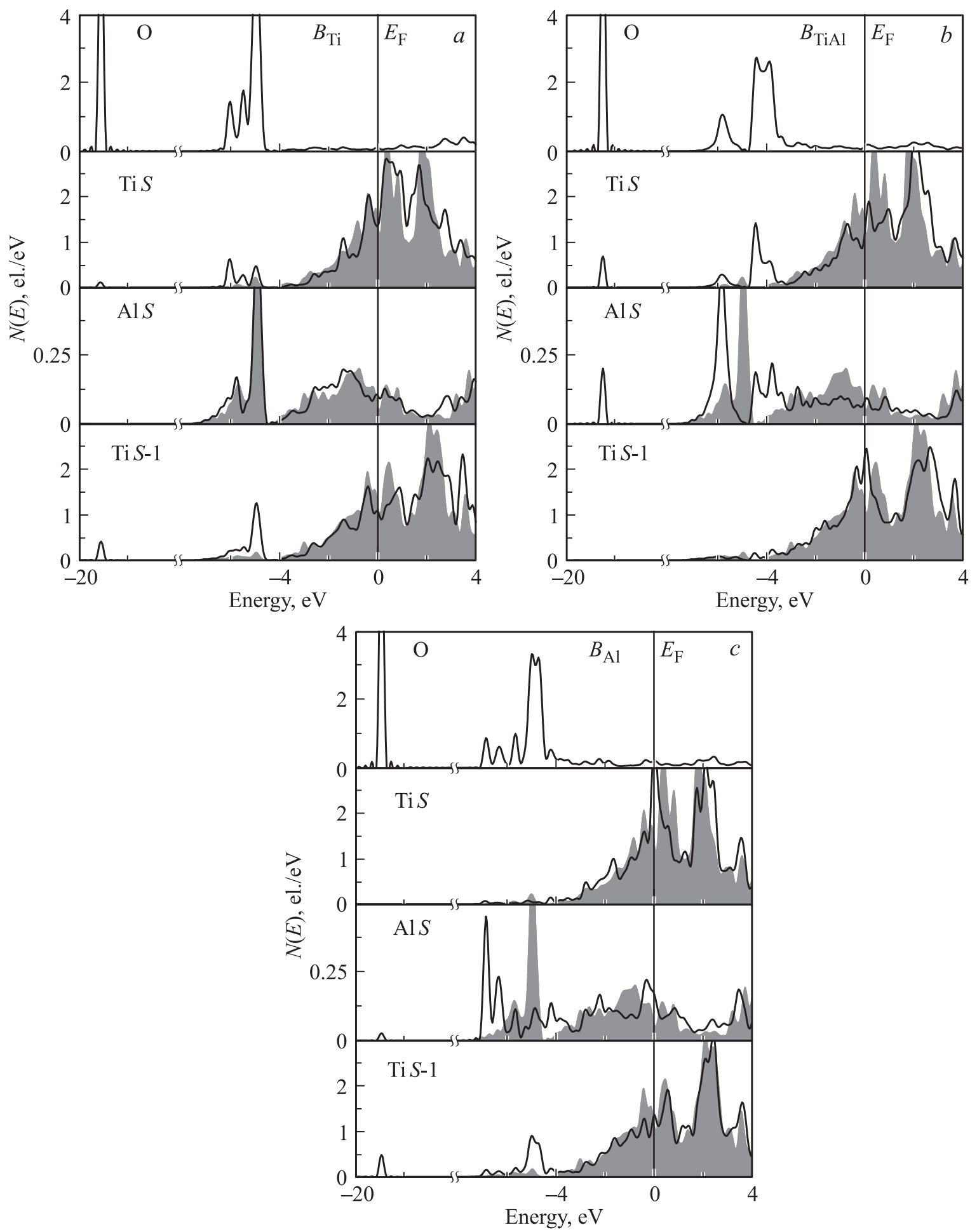

Рис. 7. Локальные плотности электронных состояний кислорода и ближайших к нему атомов поверхностного $(S)$ или подповерхностного $(S-1)$ слоя при адсорбции кислорода в позициях $B_{\mathrm{Ti}}(a), B_{\mathrm{TiAl}}(b)$ и $B_{\mathrm{Al}}(c)$. Соответствующие ПЭС атомов чистой поверхности показаны серым цветом.

дна валентной зоны титана. Поскольку атомы алюминия находятся на значительном удалении от кислорода $(3.72 \AA)$, их ПЭС практически не изменяются (рис. 7, $a$ ).

Второй по предпочтительности (энергия адсорбции на $1.57 \mathrm{eV}$ ниже) является мостиковая $B_{\text {TiAl-позиция, }}$ однако ориентация этого моста (вдоль направления $[11 \overline{2} 0])$ отличается от ориентации титанового моста в предыдущем случае (вдоль [0001]). В этом случае атомы титана и алюминия поверхностного слоя изначально располагались существенно ближе (на $1.77 \AA$ ) друг к 
другу, чем атомы титана в $B_{\text {Ti-позиции. Адсорбция }}$ кислорода в позиции смешанного моста приводит к разному смещению атомов $\mathrm{Al}$ и Ті в сторону вакуума (на $0.11-0.21 \AA$ ), при этом атомы титана расположены выше атомов алюминия на $0.16 \AA$. Кроме того, наблюдается латеральное смещение атомов на $\sim 0.1 \AA$ по направлению друг к другу. Из рис. 7, $b$ видно, что $\mathrm{O} p$-зона расщепляется в результате взаимодействия с ближайшими поверхностными атомами, причем первый небольшой пик, расположенный при энергии $-5.8 \mathrm{eV}$, обусловлен преимущественно взаимодействием c $s$-состояниями алюминия, тогда как в районе двойного пика (от -4.7 до $-3.5 \mathrm{eV}$ ) кислород в основном взаимодействует с Ti $d$ - и $\mathrm{Al} p$-состояниями. Кривые ПЭС подповерхностных атомов титана указывают на то, что эти атомы практически не вовлекаются во взаимодействие с кислородом, а небольшие изменения ПЭС вблизи уровня Ферми отражают непрямое взаимодействие через гибридизацию с поверхностными металлическими атомами.

Значительно меньшая величина энергии адсорбции (на $1.71 \mathrm{eV}$ ) для $B_{\mathrm{Al}}$-позиции, чем в случае $B_{\mathrm{Ti}}$-Позиции, является отражением того факта, что поверхностные атомы алюминия слабее взаимодействуют с кислородом, чем с титаном. Напомним, что делокализованные $3 s-$ и $3 p$-состояния сильнее смещаются при взаимодействии с кислородом, чем локализованные $d$-орбитали (рис. $7, c)$, однако гибридизация $\mathrm{O} s, p-\mathrm{Ti} d$ сильнее, чем $\mathrm{O} s, p-\mathrm{Al} s, p$. Взаимодействие с подповерхностными атомами титана, которые расположены на одинаковом расстоянии от кислорода в обеих позициях, практически подобно, что и отражают кривые ПЭС (рис. 7,a,c). Механизм взаимодействия в вершинных позициях на поверхности практически не зависит от ориентации поверхности. Таким образом, большая энергия адсорбции

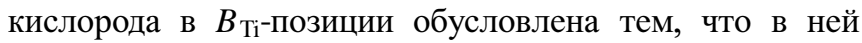
кислород взаимодействует с двумя атомами титана как поверхностного, так и подповерхностного слоя, тогда как в других позициях число ближайших атомов титана уменьшается, а замена одного из атомов на атом

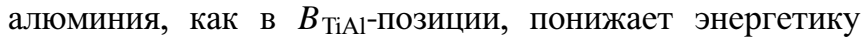
связи кислорода за счет уменьшения гибридизационного О $s, p-\mathrm{Al} s, p$-вклада.

Поскольку другие окончания поверхностей (112̄0) и (1100) сплава $\mathrm{Ti}_{3} \mathrm{Al}$ не являются стабильными, адсорбция кислорода на них не обсуждается. Отметим, что на поверхностях с большим содержанием титана в поверхностном и подповерхностном слоях энергия адсорбции увеличивается, тогда как на поверхности $\mathrm{Ti}_{3} \mathrm{Al}(1 \overline{1} 00)_{\mathrm{Ti}-\mathrm{Al}-2}$, напротив, энергия адсорбции в мостиковых $B_{\mathrm{Ti}^{-}}$и $B_{\mathrm{Al}}$-позициях несколько уменьшается, поскольку в этом случае адатом кислорода взаимодействует не с двумя подповерхностными атомами титана, a находится над одним из подповерхностных атомов (Al или Ti). Такое взаимодействие, как показывают расчеты для вершинных позиций, является энергетически менее выгодным.
3.4. Итоговые замечания. Таким образом, наши расчеты показывают, что на всех трех рассмотренных низкоиндексных поверхностях сплава $\mathrm{Ti}_{3} \mathrm{Al}$ максимальные энергии связи кислорода соответствуют его адсорбции в обогащенных титаном позициях. Это должно способствовать формированию оксидов титана на поверхности $\mathrm{Ti}_{3} \mathrm{Al}$. Действительно, как показано в ряде работ $[48,49]$, окисление титана наблюдается при комнатных температурах и предшествует окислению алюминия на поверхности как $\mathrm{Ti}_{3} \mathrm{Al}$, так и TiAl. Бо́льшая растворимость кислорода в сплаве $\mathrm{Ti}_{3} \mathrm{Al}$, чем в других сплавах, связывается с предпочтительностью внедрения кислорода в октаэдрические позиции $\left(\mathrm{Ti}_{6}\right)$ с титаном в ближайших соседях. Например, в сплаве TiAl имеются только позиции, содержащие два и четыре атома алюминия $\left(\mathrm{Al}_{2} \mathrm{Ti}_{4}\right.$ и $\left.\mathrm{Al}_{4} \mathrm{Ti}_{2}\right)$. Энергия адсорбции в $O 1$-позиции $\left(\mathrm{Ti}_{6}\right)$ в сплаве $\mathrm{Ti}_{3} \mathrm{Al}$ на $\sim 2.2 \mathrm{eV}$ больше, чем в соответствующей октаэдрической позиции $\left(\mathrm{Al}_{2} \mathrm{Ti}_{4}\right)$ в TiAl $[15,16]$. В то же время при высоких температуpax на поверхности $\mathrm{Ti}_{3} \mathrm{Al}$ наблюдается формирование тонкого слоя $(\sim 0.2-0.5 \mathrm{~nm})$ оксида алюминия [21], что соответствует оксидной пленке, содержащей двапять атомных слоев кислорода. Такое поведение предполагает поверхностную сегрегацию $\mathrm{Al}$, что позволяет адсорбированному кислороду взаимодействовать с алюминием [21]. Небольшая толщина предполагает скорее формирование островков, которые растут латерально на поверхности, чем сплошной пленки оксида алюминия. Как отмечалось выше, увеличение содержания алюминия в поверхностном слое приводит к понижению поверхностной энергии независимо от ориентации поверхности сплава $\mathrm{Ti}_{3} \mathrm{Al}$. Непосредственные оценки влияния сегрегации алюминия на поверхностную энергию $\mathrm{Ti}_{3} \mathrm{Al}(0001)$, проведенные в [18], также подтвердили, что образование антиструктурных дефектов алюминия в поверхностном слое энергетически выгодно. Кроме того, согласно данным [18], адсорбция кислорода также способствует сегрегации алюминия. Отметим, что энергии активации самодиффузии $\mathrm{Al}$ и $\mathrm{Ti}$ в $\mathrm{Ti}_{3} \mathrm{Al}$ равны 395 и $288 \mathrm{~kJ} / \mathrm{mol}(4.09$ и $2.99 \mathrm{eV})$ [50]. Очевидно, что рост оксида алюминия на поверхности сплава ограничен потоком атомов алюминия к поверхности. Более того, для диффузии алюминия необходимо присутствие вакансий алюминия на интерфейсе сплав/оксид. Последнее приводит к формированию обогащенной титаном области. Считается, что уменьшение числа связей $\mathrm{Al}-\mathrm{Ti}$ в этой области увеличивает активность титана, а дефектность пленки оксида алюминия позволяет ему диффундировать к поверхности, где и происходит его окисление. Таким образом, в эксперименте [21] обнаруживается формирование пленки оксида титана над тонкой сильно дефектной пленкой оксида алюминия. Наше моделирование адсорбции кислорода на поверхности $\mathrm{Ti}_{3} \mathrm{Al}(0001)$ с антиструктурными Al-дефектами в поверхностном слое показывает, что кислород взаимодействует с алюминием при низких концентрациях, а с увеличением концентрации кислорода атомы титана смещаются к поверхности, 
где они координированы кислородом, как в $\mathrm{TiO}_{2}$. Практически подобное поведение наблюдалось на смешанном окончании поверхности $\mathrm{TiAl}_{3}(001)$ в нашей работе [17].

В заключение заметим, что хотя прямое моделирование высокотемпературного окисления поверхности сплавов $\mathrm{Ti}-\mathrm{Al}$ затруднено в рамках методов ФЭП, однако эти методы, позволяющие получить информацию для основного состояния сплавов, интенсивно используются для изучения адсорбции кислорода. Считается, что для понимания механизмов высокотемпературного окисления поверхности необходимо выявление основных тенденций взаимодействия кислорода с атомами поверхностных слоев, которые определяются электронной подсистемой и практически не зависят от температуры.

\section{4. Заключение}

В работе представлены результаты расчетов сорбции кислорода в объеме на низкоиндексных поверхностях сплава $\mathrm{Ti}_{3} \mathrm{Al}$, выполненных методом проекционных присоединенных волн в рамках теории функционала плотности. Показано, что сорбция кислорода в объеме сплава наиболее предпочтительна в обогащенной титаном ок-

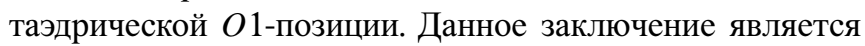
справедливым для всех алюминидов титана [15-17,39] и согласуется с имеющимися экспериментальными данными [40].

Расчеты поверхностных энергий низкоиндексных поверхностей сплава $\mathrm{Ti}_{3} \mathrm{Al}$ показали, что в $\mathrm{Al}$-обогащенной области стабильной является поверхность $(11 \overline{2} 0)_{\mathrm{Ti}-\mathrm{Al}}$ со смешанным окончанием, тогда как поверхность $(1 \overline{1} 00)_{\text {Ti-Al-1 }}$ со смешанным окончанием более стабильна в Ті-обогащенном пределе. Разница в поверхностных энергиях этой структуры и базальной поверхности (0001) составляет лишь $0.012 \mathrm{~J} / \mathrm{m}^{2}$, что находится на пределе точности расчета. Показано, что на стехиометрической поверхности $\mathrm{Ti}_{3} \mathrm{Al}(0001)$ наиболее предпочтительной позицией для адсорбции кислорода является трехкратно координированная $F 1$-позиция, в которой кислород взаимодействует с тремя поверхностными атомами титана. На поверхности $\mathrm{Ti}_{3} \mathrm{Al}(11 \overline{2} 0)_{\mathrm{Ti}-\mathrm{Al}}$ со смешанным окончанием кислород предпочтительнее адсорбируется в H1-позиции в центре титанового треугольника, тогда как

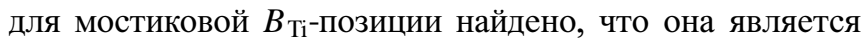
более предпочтительной для кислорода на поверхности

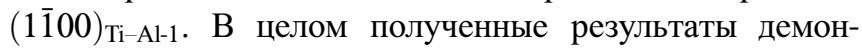
стрируют повышение энергии адсорбции кислорода при увеличении содержания титана в ближайшем окружении кислорода, а также при повышении концентрации титана в сплавах $\mathrm{Ti}-\mathrm{Al}$. Отметим, что в настоящей работе затронут лишь микроскопический аспект взаимодействия кислорода на низкоиндексных поверхностях. Хотя в расчетах не учитываются многие эффекты, в том числе влияние температуры, структурные превращения на поверхности и другие, тем не менее расчеты из первых принципов позволяют достаточно корректно оценивать энергию связи кислорода в объеме и на поверхности и получить информацию о начальном этапе окисления.

\section{Список литературы}

[1] Z. Li, W. Gao. In: Intermetallics research progress / Eds Y.N. Berdovsky. Nova Science Publ., N.Y. (2008). P. 1.

[2] Я. Полмеар. Легкие сплавы: от традиционных до нанокристаллов. Техносфера, М. (2008). 464 с.

[3] F.H. Froes, C. Suryanarayana, D. Eliezer. J. Mater. Sci. 27, 5113 (1992).

[4] Y. Umakoshi, M. Yamaguchi, T. Sakagami, T. Yamane. J. Mater. Sci. 24, 1599 (1989).

[5] F. Dettenwanger, M. Schütze. Oxid. Met. 54, 121 (2000).

[6] R.G. Reddy. JOM 54, 65 (2002).

[7] M.P. Brady, P.F. Tortorelli. Intermetallics 12, 779 (2004).

[8] J.G. Speight. Lange's handbook of chemistry. 16th ed. McGraw-Hill, N.Y. (2005). P. 124.

[9] A.Y. Lozovoi, A. Alavi, M.W. Finnis. Phys. Rev. Lett. 85, 610 (2000).

[10] H. Li, S. Wang, H. Ye. J. Mater. Sci. Technol. 25, 569 (2009).

[11] S.-Y. Liu, J.-X. Shang, F.-H. Wang, Y. Zhang. Phys. Rev. B 79, 075419 (2009)

[12] L. Wang, J.-X. Shang, F.-H. Wang, Y. Zhang, A. Chroneos. J. Phys.: Condens. Matter. 23, 265009 (2011).

[13] Y. Song, J.H. Dai, R. Yang. Surf. Sci. 606, 852 (2012).

[14] L. Wang, J.-X. Shang, F.-H. Wang, Y. Chen, Y. Zhang. Acta Mater. 61, 1726 (2013).

[15] S.E. Kulkova, A.V. Bakulin, Q.M. Hu, R. Yang. Comp. Mater. Sci. 97, 55 (2015).

[16] А.В. Бакулин, С.Е. Кулькова, Ц.М. Ху, Р. Янг. ЖЭТФ 147, 292 (2015).

[17] А.М. Латышев, А.В. Бакулин, С.Е. Кулькова, Ц.М. Ху, Р. Янг. ЖЭТФ 150, 1140 (2016).

[18] S.-Y. Liu, S. Liu, D. Li, T.M. Drwenski, W. Xue, H. Dang, S. Wang. Phys. Chem. Chem. Phys. 14, 11160 (2012).

[19] L.-J. Wei, J.-X. Guo, X.-H. Dai, Y.-L. Wang, B.-T. Liu. Surf. Rev. Lett. 22, 1550053 (2015).

[20] L.-J. Wei, J.-X. Guo, X.-H. Dai, L. Guan, Y.-L. Wang, B.-T. Liu. Surf. Interface Anal. 48, 1337 (2016).

[21] V. Maurice, G. Despert, S. Zanna, P. Josso, M.-P. Bacos, P. Marcus. Acta Mater. 55, 3315 (2007).

[22] P.E. Blöchl. Phys. Rev. B 50, 17953 (1994).

[23] G. Kresse, J. Joubert. Phys. Rev. B 59, 1758 (1999).

[24] G. Kresse, J. Hafner. Phys. Rev. B 48, 13115 (1993).

[25] G. Kresse, J. Furthmüller. Phys. Rev. B 54, 11169 (1996).

[26] G. Kresse, J. Furthmüller. Comp. Mater. Sci. 6, 15 (1996).

[27] J.P. Perdew, K. Burke, M. Ernzerhof. Phys. Rev. Lett. 77, 3865 (1996).

[28] H.J. Monkhorst, J.D. Pack. Phys. Rev. B 13, 5188 (1976).

[29] H. Shi, C. Stampfl. Phys. Rev. B 76, 075327 (2007).

[30] K.P. Huber, G. Herzberg. Molecular spectra and molecular structure IV: constants of diatomic molecules. Van Nostrand Reinhold, N.Y. (1979). 716 p.

[31] Y.L. Liu, L.M. Liu, S.Q. Wang, H.Q. Ye. Intermetallics 15, 428 (2007).

[32] M.H. Yoo, J. Zou, C.L. Fu. Mater. Sci. Eng. A 192/193, 14 (1995).

[33] W.B. Pearson. A handbook of lattice spacing and structures of metals and alloys. 1st ed. Pergamon Press, N.Y. (1958). $1054 \mathrm{p}$. 
[34] K. Tanaka., K. Okamoto, H. Inui, Y. Minonishi, M. Yamaguchi, M. Koiwa. Philos. Mag. A 73, 1475 (1996).

[35] F.D. Murnaghan. Proc. Natl. Acad. Sci. USA 30, 244 (1944).

[36] T. Hong, T.J. Watson-Yang, X.-Q. Guo, A.J. Freeman, T. Oguchi, J.-H. Xu. Phys. Rev. B 43, 1940 (1991).

[37] D. Sornadurai, B. Panigrahi, Ramani. J. Alloys Compd. 305, 35 (2000).

[38] D. Music, J.M. Schneider. Phys. Rev. B 74, 174110 (2006).

[39] Y. Wei, H.-B. Zhou, Y. Zhang, G.-H. Lu, H. Xu. J. Phys.: Condens. Matter 23, 225504 (2011).

[40] C.Y. Jones, W.E. Luecke, E. Copland. Intermetallics 14, 54 (2006).

[41] R. Hultgren, P.D. Desai, M. Gleiser, D.T. Hawkins. Selected values of thermodynamic properties of binary alloys. American Society for Metals, Metals Park, OH (1973). $1435 \mathrm{p}$.

[42] F.R. de Boer, R. Boom, W.C.M. Mattens, A.R. Miedema, A.K. Niessen. Cohesion in metals: transition metal alloys. North Holland, Amsterdam (1989). 758 p.

[43] Smithells metals references book / Eds E.A. Brandes, G.B. Brook. 7th ed. Butterworth-Heinemen, London (1992). $1800 \mathrm{p}$.

[44] L. Wang, J.-X. Shang, F.-H. Wang, Y. Zhang. Appl. Surf. Sci. 276, 198 (2013).

[45] G. Henkelman, B.P. Uberuaga, H. Jónsson. J. Chem. Phys. 113, 9901 (2000).

[46] Т.И. Спиридонова, А.В. Бакулин, С.Е. Кулькова. ФТТ 57, 1873 (2015).

[47] S.E. Kulkova, A.V. Bakulin, S.S. Kulkov, S. Hocker, S. Schmauder. Phys. Scripta 90, 094010 (2015).

[48] M.R. Shanabarger. Mater. Sci. Eng. A 153, 608 (1992).

[49] M.R. Shanabarger. Appl. Surf. Sci. 134, 179 (1998).

[50] J. Rüsing, C. Herzig. Intermetallics 4, 647 (1996). 